\title{
Dissipation Behavior of Thiophanate-Methyl in Apple and Strawberry Fruits under Open Field Conditions
}

\author{
Dalia, E. El-Hefny ${ }^{1}$; Rania, M. Abdel-Hamid ${ }^{1}$, and Maher S.Salma ${ }^{2}$
}

\begin{abstract}
Thiophanate-methyl is an effective fungicide on several food crops. In the present study, dissipation of residue levels of thiophanate-methyl in apple and strawberry fruits under open field conditions were studied using high performance liquid chromatography with diode array detection (HPLC-DAD).The extraction and clean-up were conducted by QuEChERS method. The limit of quantitation and detection were 0.01 and $0.003 \mathrm{mg} / \mathrm{kg}$, respectively. The results suggest that the thiophanatemethyl dissipation curves followed the first order kinetics and its half-life values were (1.01) and (1.26) days for apple and strawberry, respectively. The residues in apple and strawberry were below the codex maximum residue limit (MRL) $(0.5$ and $0.1 \mathrm{mg} / \mathrm{kg})$ after 8 and 4 days of the application, respectively.
\end{abstract}

Key words: Residues, Thiophanate-methyl, apple, strawberry.

\section{INTRODUCTION}

Thiophanate-methyl dimethyl [4,4'-(o-phenylene) bis (3-thioallophanate)] is a broad spectrum systemic fungicide which is widely used to control important fungal diseases in fruits, vegetables, field and plantation crops (Traina et al. 1998). Which upon spraying of plant is quickly absorbed on its surface and easily transported to the various parts of the plant as methyl benzimidazol carbamate (MBC). Biochemical transformations in the presence of plant enzyme or sunlight are responsible for the conversion of thiophanate methyl to MBC (Buchenauer et al. 1973a, Buchenauer et al. 1973b; Soeda et al. 1972).

The strawberry is a perennial plant of considerable economic importance. It is cultivated on commodity plantations both for the purposes of industrial processing and for direct consumption. Egypt has been among the top five strawberries producing countries since the year 2000 (Malhat et al., 2014). Also, apple orchard has been planted in the large area in Egypt. and strawberry fruit.

The QuEChERS “Quick, Easy Cheap, Effective Rugged and Safe"method is employed frequently as a sample preparation methodology for multi-residue pesticide analysis and has been modified and validated for the detection of a broad range of pesticides in food, including highly polar pesticides, and highly acidic and basic ones (Anastassiades et al. 2003; Lehotay et al., 2010; Park et al., 2011; Payá et al., 2007). This method involves extraction with acetonitrile and partitioning after the addition of a salt mixture. The final extract in acetonitrile is readily to analysis of thiophanate-methyl by HPLC.

The maximum residue limits (MRL) regulations require a pre-harvest intervals (PHI) to ensure the dissipation of pesticide below the proposed MRL at harvest time (Zewail et al.,2015;Abdella et al., 2015). It is worth to note that, there are many factors influencing residue dissipation rates. Amongst are chemical formulations, application factors, crop and environmental factors and residue decline factors. So, the study of pesticide persistence and residual behavior gives an idea about the pre-harvest intervals (PHI) that should be followed after pesticide application and harvesting. These waiting periods should be recommended to be sure that residues are below tolerance levels before marketing in order to minimize the health hazards. (Abdel-Hamid, 2013)

The purpose of the this study is to determine residues of Thiophanate-methyl on apple and strawberry at different time intervals after application, so as to avoid harmful to health consumers to these fruits. To achive that the study aimed to estimate the pre-harvest interval values (PHI),for the issuance of a recommendation to consumers.

\section{MATERIALS AND METHODS}

Pesticide used.

\section{Thiophanate-methyl}

dimethyl 4,4'-(o-phenylene)bis(3-thioallophanate)

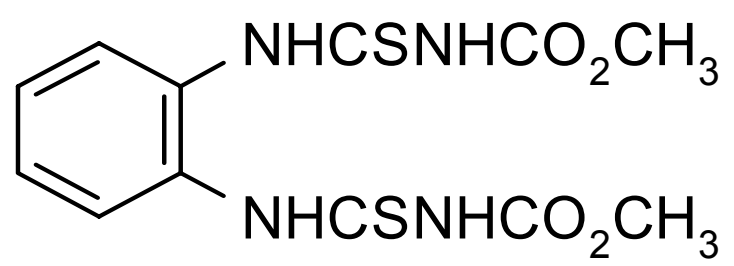

${ }^{1}$ Pesticide Laboratory, Agricultural Research Center, Dokki,

Giza, Egypt.

${ }^{2}$ Pesticide Chem. and Technology, Fac.of Agric.,

Alexandria Universty, Egypt

Received February 27, 2017, Accepted March 22, 2017 


\section{Chemicals and reagents.}

Acetone, Acetonitrile and methanol were supplied by SDS (France in HPLC grade quality). Disodiumhydrogencitratesesquihydrate and trisodium citrate dehydrate (Sigma-Aldrich). Anhydrous magnesium sulfate and sodium chloride (El-Nasr pharmaceutical chemicals Co., Egypt), were activated by heating at $135{ }^{\circ} \mathrm{C}$ overnight in the oven, cold and kept in desiccators before usage.

Analytical standards of thiophenate-methyl (98\% purity) was supplied by Sumitomo Corporation, Egypt . Formulation (Topisin-M 70\% WP) was obtained from Nippon Soda Co., Ltd (Tokyo, Japan).

\section{Preparation of standard solutions.}

Individual solution $(100 \mu \mathrm{g} / \mathrm{ml})$ reference standard of thiophenate-methyl was prepared in acetonitrile in $100 \mathrm{ml}$ volumetric flask. The successive working dilution and spiking standard solution for HPLC analysis were prepared daily by diluting the stock solution. All standard and working solutions were stored at $4{ }^{\circ} \mathrm{C}$.

\section{Instrument and apparatus.}

The HPLC system was an Agilent 1100 series equipped with an analytical column $(150 \mathrm{~mm} \times 4.6 \mathrm{~mm}$ id $\times 5 \mu \mathrm{m}$ ODS) attached to a photodiode array detector. High speed centrifuged vortex and falcon centrifuge tube.

\section{Field trials:}

The field trials, including the dissipation study were carried out at El-Qalubia Governorate, Egypt in 2016. The plants at fruiting stage were sprayed with Topsin $\mathrm{M}$ $70 \%$ WP with $60 \mathrm{gm}$. $/ 100 \mathrm{~L}$. for strawberry and 65 $\mathrm{gm} / 100 \mathrm{~L}$ for apple from the commercial products at the recommended dose as the label indicated. Knapsack sprayer fitted with one nozzle was used for spraying of the tested pesticide. One plot of each treatment was left untreated as control. Replicate samples, one $\mathrm{kg}$ strawberry fruits and two kg apple fruits were collected at random from each plot at intervals of one hour after application (zero time), 1, 3, 7, 10 and 15 days. As soon as the fruits were picked up, kept in polyethylene bags and transferred in ice box to the laboratory. Samples were roughly cut with a knife into small pieces and homogenized for at least $30 \mathrm{Sec}$. The homogeneous matrix was stored in sealable plastic bag at $-20{ }^{\circ} \mathrm{C}$ until the preparation day.the homogenates were kept in freezer for the next steps.

\section{Analytical method}

\section{Extraction and cleanup:}

The apple and strawberry fruit samples were extracted and cleaned up using a QuEChERS methodology (EURL-FV, 2010-M1).

For the extraction procedure, $10 \mathrm{~g}( \pm 0.1)$ of the frozen samples homogenate was weighted into $50 \mathrm{ml}$ falcon centrifuge tubes. Then $10 \mathrm{ml}$ of acetonitrile were added, the screw cap was closed and the tube vigorously shaken for 1 min using a vortex mixer at maximum speed. After addition of $1 \mathrm{~g}$ sodium chloride, $4 \mathrm{~g}$ anhydrous magnesium sulfate, $1 \mathrm{~g}$ Sodium Citrate $2 \mathrm{H}_{2} \mathrm{O}$ and $0.5 \mathrm{~g}$ Sodium-hydrogen Citrate1.5 $\mathrm{H}_{2} \mathrm{O}$, the mixture was mixed by vortexed for $1 \mathrm{~min}$ and centrifuged for $5 \mathrm{~min}$ at $4000 \mathrm{rpm}$ at $5{ }^{\circ} \mathrm{C}$ using a refrigerated centrifuge.

Upper acetonitrile layer $(2 \mathrm{ml})$ was transferred to a $15 \mathrm{ml}$ falcon centrifuge tube and cleanup using dispersive solid phase extraction with $25 \mathrm{mg}$ PSA and $150 \mathrm{mg}$ anhydrous magnesium sulfate and $10 \mathrm{mg} \mathrm{GCB}$ (for each $1 \mathrm{ml}$ of acetonitrile), the tube was vortexed for $1 \mathrm{~min}$ and then centrifuged for $5 \mathrm{~min}$ at $4000 \mathrm{rpm} .1 \mathrm{ml}$ extract was transferred to a vial after filtered through a $0.22 \mu \mathrm{m}$ PTFE filter (Millipore, Billerica. MA) for HPLC- DAD analysis.

\section{HPLC determination.}

Thiophanate-methyl residues were determined by HPLC system. The chromatographic conditions were as follows: an Agilent 1100 series equipped with an analytical column $(150 \mathrm{~mm} \times 4.6 \mathrm{~mm}$ id, $\times 5 \mu \mathrm{m}$ ODS $)$ attached to a photodiode array detector. Flow rate of mobile phase acetonitrile $45 \%$ + methanol $40 \%$ + water $15 \%$ ) was $0.7 \mathrm{ml} / \mathrm{min}$ and injection volume was $20 \mathrm{ul}$. Detection wavelength was set at $230 \mathrm{~nm}$. The retention time of thiophanate-methyl was $4.5 \mathrm{~min}$. The residues in the real samples were tentatively identified by comparing the retention time (Rt) of the sample peaks with the Rt of the injected standard.

\section{Statistical analysis.}

The dissipation kinetics of thiophanate-methyl residues in apple and strawberries were determined by plotting residue concentration against elapsed time after application, and equations of best curve fit with maximum coefficients of determination $\left(\mathrm{R}^{2}\right)$ were determined.

\section{RESULTS and DISCUSSION \\ Method Validation.}

According to SANCO/1257/2013 (SANCO, 2013) within laboratory method validation was performed to provide evidence that the method is fit for the extraction and quantitative determination of thiophanate-methyl in 
apple and strawberry fruits. The method was validated following a conventional validation procedure that included the following parameters: (Linearity) multilevel calibration of thiophanate-methyl was diluted either with pure solvent in series at $(5,2.5,1.25,0.5$, $0.2,0.1,0.01) \mu \mathrm{g} / \mathrm{ml}$ for HPLC analysis, (Matrix effect) comparing the response produced from the thiophanatemethyl in pure solvent solution with the samples were first extracted and then spiked with thiophanate-methyl in the same solvent at the same concentration level, (Selectivity and Sensitivity). determined limit of quantification (LOQ), limit of detection (LOD), Trueness (bias) five replicates were used to check the recovery at the levels $(1,0.1$, and 0.01$) \mathrm{mg} /$ and Repeatability Precision (RSDr).

Linearity.

For the preparation of calibration curves, thiophanate-methyl standard was diluted either with pure acetonitrile in series at $(5,2.5,1.25,0.5,0.2,0.1$, $0.01 \mathrm{mg} / \mathrm{kg}$ ) standard calibration curve of thiophanatemethyl was constructed by plotting analyte concentrations against peak areas at $230 \mathrm{~nm}$. The standard curve equation was:

$y=161.3 x+4.9349$ where $y=$ peak area and $x=$ concentration $(\mathrm{mg} / \mathrm{kg})$ with correlation coefficient $\left(R^{2}=0.9999\right)$, for thiophanate-methyl in all cases, was obtained for the solvent. The fit of the calibration was plotted and inspected by calculation of the residuals.

\section{Matrix effect and limit of quantification LOQ.}

The pesticide residue analysis study, the injected sample contained large amounts of the unavoidably present co-extractives which are responsible for the matrix effects occurring on the injector. The matrix effect was investigated by comparing the slops of calibration curves at $(5,2.5,1.25,0.5,0.2,0.1,0.01$ $\mathrm{mg} / \mathrm{kg}$ ) of thiophanate-methyl in apple and strawberry and in pure solvent. The $\%$ ME could be negative or positive and would be classified in three categories: no matrix effect (between $-20 \%$ and $20 \%$ ), medium matrix effect (between $-50 \%$ and $-20 \%$ or $-50 \%$ and $20 \%$ ) and strong matrix effect (below $-50 \%$ or above $50 \%$ ) Ferrer, et al., 2011 and Saber et al., 2016. The results in fig (2) showed that the matrix effect were $-3.56 \%$ for apple and $-1.63 \%$ for strawberry which indicated that no interfering endogenous peak appeared and did not significantly suppress or enhance the response of the instrument.

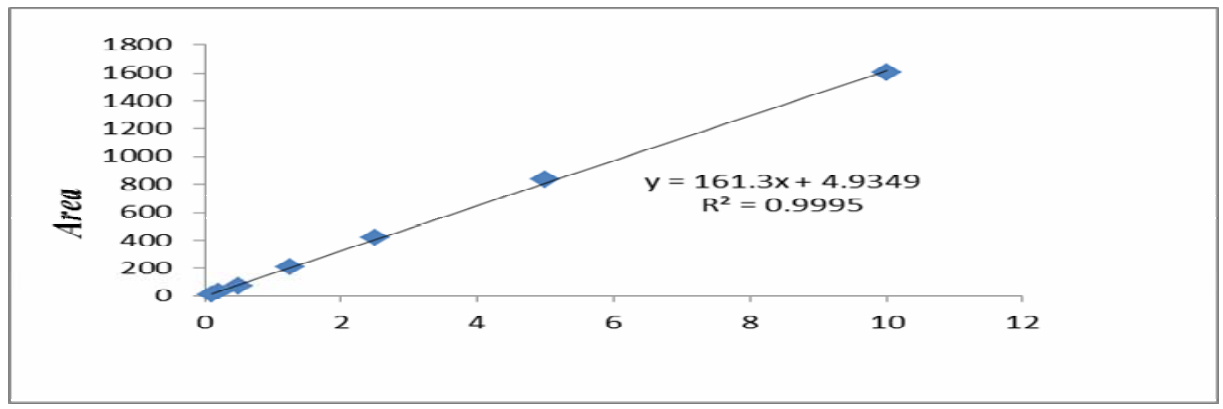

Fig.1. Calibration curve of thiophanate-methyl with HPLC analysis.

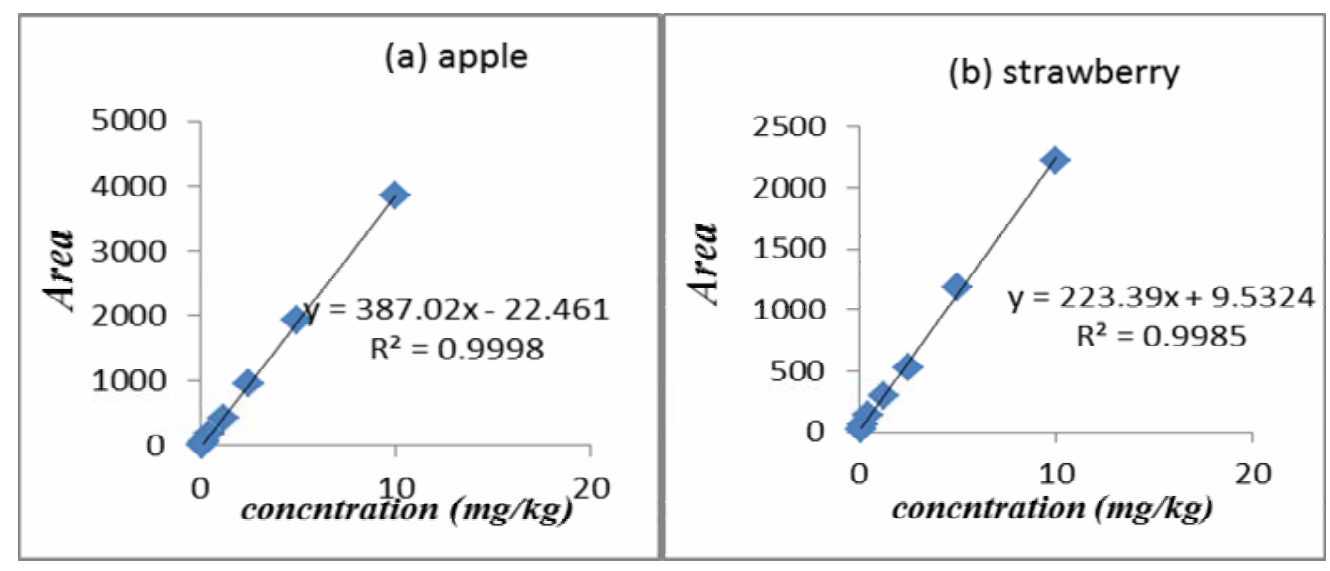

Fig.2. Matrix effect of thiophanate-methyl in apple and strawberry fruits with HPLC. 
The lowest validated level of thiophanate-methyl with acceptable precision and trueness LOQ was 0.01 $\mathrm{mg} / \mathrm{kg}$ for HPLC analysis in apple and strawberry. According to SANCO/1257/2013 (SANCO, 2013), the LOQ values are acceptable where $L O Q \leq M R L$.

\section{Trueness and precision (RSDr).}

The trueness or mean of recovery was carried out in 5 replicates at 3 fortification levels $(1,0.1,0.01 \mathrm{mg} / \mathrm{kg})$ by spiking $10 \mathrm{~g}$ of blank samples (apple and strawberry) with standard solution (table1). The obtained mean recoveries range from 85.29 to $100.68 \%$ with $\mathrm{RSD}$ ranged from 0.99 to 3.12 for apple and 88.002 to $99.95 \%$ with RSD ranged from 0.99 to 2.12 for strawberry. According to SANCO/1257/2013 (SANCO, 2013), the obtained mean recoveries were within the acceptable range (70-120\%). So, the value confirmed that QuEChERs sample preparation coupled with HPLC-DAD analysis is suitable for the determination of thiophanate-methyl residue in apple and strawberry.

The repeatability precision (RSDr) involved repeat of recovery levels $(1,0.1,0.01 \mathrm{mg} / \mathrm{kg})$, five replicates for each level per day on three different days. The (RSDr) value ranged from 0.98 to 3.66 for apple and 1.03 to 2.41 for strawberry According to SANCO/1257/2013 (SANCO, 2013) the obtained (RSDr) value was within the acceptable range $\leq 20 \%$ (table1).

\section{Dissipation of thiophanate-methyl in apple and strawberry fruits.}

For dissipation of thiophanate-methyl in apple and strawberries, exponential relationships were found to be applicable corresponding to the general first-order kinetics equation:

\section{$C t=C 0 e^{-k t}$}

where $C t$ represents the concentration of the pesticide residue at the time of $t, C O$ represents the initial deposits after application and $\mathrm{k}$ is the constant rate of pesticide dissipation per day. From this equation, the dissipation half-life values were calculated using the following equation $\left(t_{1 / 2}=\ln 2 / \mathrm{k}\right)$.

The results of dissipation of thiophanate-methyl on strawberry and apple are presented in Table (2) Average initial deposit of thiophanate-methyl on strawberry and apple were found to be $2.75 \pm 0.058$ and $4.93 \pm 0.11 \mu \mathrm{g} \mathrm{g}^{-}$ 1 , respectively. On the first day, residues degraded highly and reached to $1.66 \pm 0.055$ and $2.50 \pm 0.10 \mu \mathrm{g} \mathrm{g}^{-1}$ showing 39.63 and $49.29 \%$ dissipation rate in strawberry and apple fruit, respectively. On the third day, the residues of thiophanate-methyl degraded to $0.15 \pm 0.055$ and $1.15 \pm 0.015 \mu \mathrm{g} \mathrm{g}^{-1}$ with a dissipation rate of 94.54 and $76.67 \%$ on strawberry and apple fruits, respectively. On the seventh day, the residues of thiophanate-methyl degraded to $0.06 \pm 0.01$ and $0.51 \pm 0.01 \mu \mathrm{g} \mathrm{g}^{-1}$ with a dissipation rate of 97.81 and $89.66 \%$ on strawberry and apple fruits, respectively. Total reduction of thiophanate-methyl residues up to $10^{\text {th }}$ day after treatments was to the extent of 98.54 and $93.71 \%$ on strawberry and apple fruits, respectively. The residues were still found to be $0.01 \pm 0.0005$ and $0.11 \pm 0.005 \mu \mathrm{g} \mathrm{g}^{-1}$ at $15^{\text {th }}$ days post treatment. The relationship between residue dissipation versus time is depicted in fig. (3) The dissipation of thiophanatemethyl in strawberry and apple fruits depends on the climatic conditions, type of application, plant species, dosage, the intervals between application and harvest (Khay, et al. 2008). Reduction in amount of residues of thiophanate-methyl over a period of time observed an exponential decrease in residue concentrations and followed first-order rate of dissipation in both crops. No residues were found in the control samples collected from control plots of the experiment.Residue decline may be attributed to volatilization that occurred during the first days following application, removal by weathering, heat decomposition, sunlight and/or UV radiation (Spynu, 1989). Additionally, the growth dilution factor might have played a significant role (Tewary et al., 2005).

The dissipation patterns of thiophenate-meythyl on appale and strawberry were found to be biphasic model. The present findings are accordance with those of many investigators, who reported that the kinetiec of pesticide degradation is commonly biphasic with avery rapid degradation rate at the beginning, followed by avery slow prolonged dissipection (Alexander,1994; Rigas et.al. ; 2007).

Table 1. Mean recovery and repeatability precision of thiophanate-methyl in apple and strawberry fruits.

\begin{tabular}{lcccc}
\hline $\begin{array}{l}\text { Spiked level }(\mathbf{m g} / \mathbf{k g}) \\
(\mathbf{n} * \mathbf{5})\end{array}$ & Strawberry & \multicolumn{2}{c}{ Apple } \\
\cline { 2 - 5 } & Mean recovery (\%+RSD) & RSDr\% & Mean recovery (\% \pm RSD) & RSDr\% \\
\hline 0.01 & $88.002 \pm 2.12$ & 2.41 & $85.29 \pm 3.12$ & 3.66 \\
0.1 & $96.23 \pm 0.99$ & 1.03 & $93.06 \pm 1.88$ & 2.02 \\
1 & $99.59 \pm 1.28$ & 1.28 & $100.68 \pm 0.99$ & 0.98 \\
\hline
\end{tabular}

$\mathrm{n}^{*}:$ number of replicates. 
Table 2. Residue levels and dissipation behavior of thiophanate-methyl on apple and strawberry fruits under field conditions

\begin{tabular}{|c|c|c|c|c|}
\hline \multirow{2}{*}{$\begin{array}{l}\text { Intervals after } \\
\text { tratment (days) }\end{array}$} & \multicolumn{2}{|c|}{ Strawberry } & \multicolumn{2}{|c|}{ Apple } \\
\hline & Residues $\left(\mu \mathrm{g} \mathrm{g}^{-1}\right)$ & \% Dissipation & Residues $\left(\mu \mathrm{g} \mathrm{g}^{-1}\right)$ & \% Dissipation \\
\hline initial* & $2.75 \pm 0.058$ & 0.00 & $4.93 \pm 0.11$ & 0.00 \\
\hline 1 & $1.66 \pm 0.055$ & 39.63 & $2.50 \pm 0.10$ & 49.29 \\
\hline 3 & $0.15 \pm 0.055$ & 94.54 & $1.15 \pm 0.015$ & 76.67 \\
\hline 7 & $0.06 \pm 0.01$ & 97.81 & $0.51 \pm 0.01$ & 89.66 \\
\hline 10 & $0.04 \pm 0.005$ & 98.54 & $0.31 \pm 0.01$ & 93.71 \\
\hline 15 & $0.01 \pm 0.0005$ & 99.63 & $0.11 \pm 0.005$ & 97.77 \\
\hline$t_{1 / 2}$ & \multicolumn{2}{|c|}{1.26} & \multicolumn{2}{|c|}{1.01} \\
\hline EU MRL & \multicolumn{2}{|c|}{0.1} & \multicolumn{2}{|c|}{0.5} \\
\hline PHI (days) & \multicolumn{2}{|c|}{4} & \multicolumn{2}{|c|}{8} \\
\hline
\end{tabular}

*initial: one hour after application.

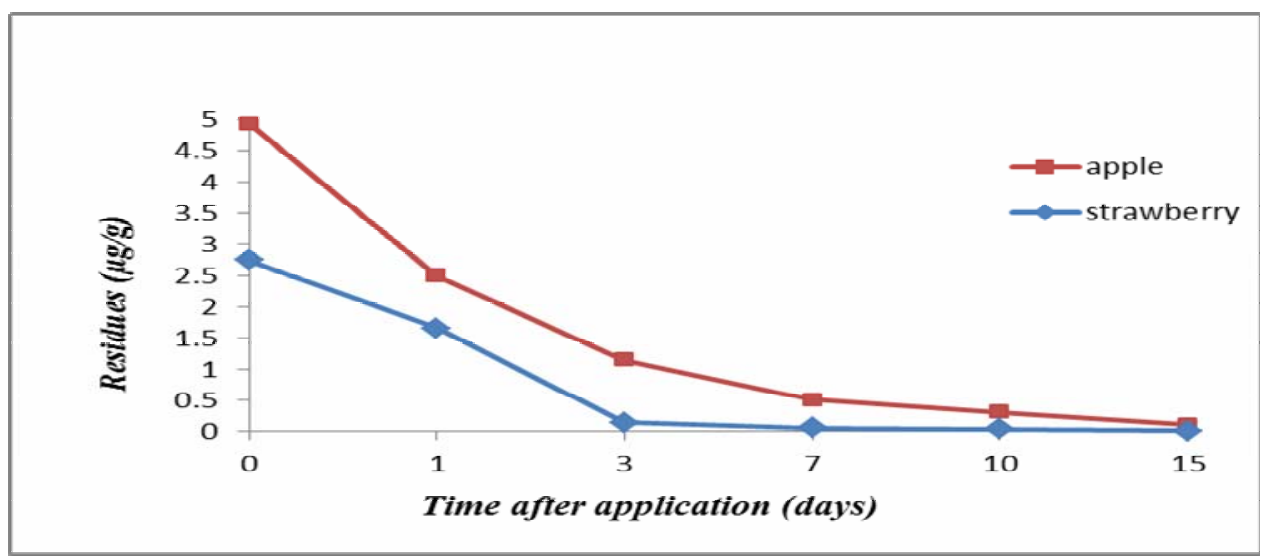

Fig. 3. The dissipation of thiophanate-methyl in strawberry and apple fruits.

Data of both crops were subjected to statistical analysis (Hoskin 1961) for calculation of half life $\left(t_{1 / 2}\right)$ and waiting period (PHI). $\mathrm{t}_{1 / 2}$ of thiophanate-methyl on strawberry and apple fruits were found to be 1.26 and 1.01 days, respectively, whereas, PHI was worked out to be 4 and 8 days for strawberry and apple fruits, respectively.

\section{REFERENCES}

Abdel-Hamid, R.M. 2013. Effect of formulation type and product source on the residue levels of some pesticides $\mathrm{Ph}$. D. Agric. Sci. (pesticides), Ain Shams University.

Abdella , H.M., Halawa, S.M. and El-Hefny, D.E. (2015). Dissipition of penconazole and imidacloprid residues in squash fruits under the Egyptian field conditions. Alex. Sci. Exch. J., 36 (4): 292-296.

Alexander,M.1994. Biodegredation and bioremediation .Academic press, San Diego,CA,USA.

Anastassiades, M., Lehotay, S., Stajnbaher, D. and Schenck, F. 2003. Fast and easy multiresidue method employing acetonitrile extraction/partitioning and "dispersive solidphase extraction" for the determination of pesticide residues in produce. J. A.O.A.C. Int., 86:412-431.
Buchenauer, H, Edgin, L.N and Grassman, F 1973b. Photochemical transformation of thiophanate methyl and thiophanate or alkyl benzimidazol-2yl-carbamate. Pest. Sci., 4:343.

Buchenauer, H, Erwin, D.C and Keen, N.T. 1973a. Systemic fungicidal effects of thiophanate methyl on verticillium wilt of cotton and its transformation to methyl-2benzimidazol carbamate in cotton plants. Phytopath. 63:1091.

EURL-FV 2010-M1. Multiresidue Method using QuEChERS followed by GC-QqQ/MS/MS and LC-QqQ/MS/MS for Fruits and Vegetables. http://www.crlpesticides.eu/library/docs/fv/CRLFV_Multiresidue_metho $d s . p d f$.

Ferrer, C., Lozano, A., Agüera, A., Jiménez, A., and Fernández, A. R. 2011. Overcoming matrix effects using the dilution approach in multiresidue methods for fruits and vegetables. J. Chrom. A, 1218: 7634-7639.

Hoskin, M. 1961. Mathematical treatments of the rate of loss of pesticide residues. FAO Plant Prot. Bull., 9:163-168. 
Khay, S., Choi, J., Abd El-Aty, A., Mamun, M., Park, B.; Goudah, H. and Shim, J. 2008. Dissipation behavior of lufenuron, benzoylphenylurea insecticide in/on chinese cabbage applied by foliar spraying under green house condition. Bull. Environ. Contam. Toxicol., 81:369-372.

Lehotay, S.J., Son, K.A., Kwon, H., Koesukwiwat, U., Fu, W. and Mastovska, K. 2010. Comparison of QuEChERS sample preparation methods for the analysis of pesticide residues in fruits and vegetables. J. Chrom. A, 1217, 25482560.

Malhat, F.,Badawy, H.M.A., Barakat, D.A. and Saber, A.N. 2014. Residues, dissipation and safety evaluation of chromofenozide in strawberry under field conditions. J.food chem., 152: 18-22.

Rigas ,F.,Papadopoulou,K.,Dristsa,V. and Doulia,D. 2007. Bioremediation of soil contaminated by lindane utilizing the fungus ganoderma austral via response surface methodology. J.Hazard Materials 140,325-332.

Park, J.Y.,Choi, J.H., Abd El-Aty, A.M.,Kim, B.M., Oh, J.H. and Do, J.A. 2011. Simultaneous multiresidue analysis of 41 pesticide residues in cooked foodstuff using QuEChERS: Comparison with classical method. Food Chem., 128, 241-253.

Payá, P., Anastassiades, M., Dorothea, M., Sigalova, I., Tasdelen, B. and José, O. (2007). Analysis of pesticide residues using the quick easy cheap effective rugged and safe (QuEChERS) pesticide multiresidue method in combination with gas and liquid chromatography and tandem mass spectrometric detection. Analy. Bioanalytical Chem., 389:1697-1714.
Saber, A.N., Malhat, F.M., Badawy, H.M.A. and Barakat, D.A. 2016. Dissipation dynamic, residue distribution and processing factor of hexythiazox in strawberry fruits under open field condition. Food Chem., 196:1108-1116.

SANCO/12571/2013 2013. Guidance document on analytical quality control and method validation procedures for pesticides residues analysis in food and feed.

Soeda, Y., Kosaka, S. and Noguchi, T. 1972. The fate of thiophanate methyl fungicide and its metabolite on plant leaves and glass plates. Agric Biol Chem 36:931.

Spynu, E.I. 1989. Predicting pesticide residues to reduce crop contamination. Rev Environ Contam Toxicol., 109:89-107.

Tewary, D., Vipin, K., Ravindranath, S.D., and Adarsh, S. 2005. Dissipation behavior of bifenthrin residues in tea and its brew. Food Control, 16: 231-237.

Traina, M.E., Fazzi, P., Macr, C., Ricciardi, C., Stazi, A.V., Urbani, E. and Mantovani, A. 1998. In vivo studies on possible adverse effects on reproduction of the fungicide methyl thiophanate. J Appl. Toxicol., 18:241-248.

Zewail.M.Z., M. M. Kandil, M.S. El-Shahaat , M.H. ElHalfway and A.M. El-Mare.2015. Residues and Dissipation of Imidacloprid, Oxamyl, and Emamectin Benzoate in Greenhouse Grown Tomato Fruits and Their Influence on Lycopene Content.Alex.Sci.Exch.J.36(1):16.

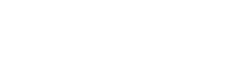 \\ سلوك الخفاءمبيد الثيوفينت ميثل في ثمار الفاح والفرالولة تهت الالروف الهقلية



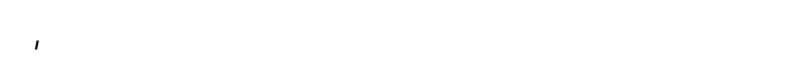



متقيك المبيد القل من الحدود القصوي المسموح بها (0. وا •, مجم/لكبم) لذا كلت قيم فترة ما قبل الحصاد

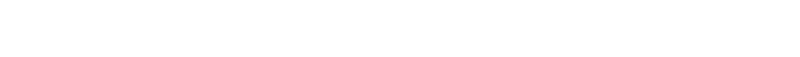

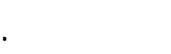

الكلمات الدالة: متقيلت، ثيرفينات ميثل، الفاح

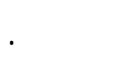

يعتبر الثيوفينات ميثل مبيد فطري فعل في كثير من

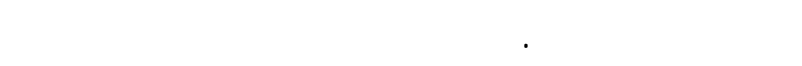

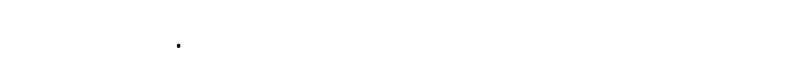
معدل إخفاء الثيوفينت ميثل في كلا من الفاح والفراولة

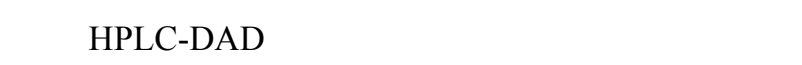

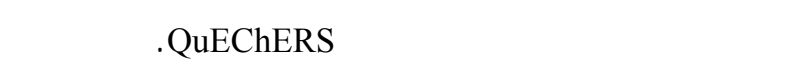
النتائج أن معدلات الإبسترجاع اللفاح كلفت بتنراوح مابين

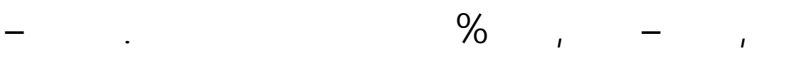


مجم/اكم. كذك أوضحت النتائج أن قيم فترات نصف 